\title{
Parking Space Reservation Behavior of Car Travelers from the Perspective of Bounded Rationality: A Case Study of Nanchang City, China
}

\author{
Yunqiang Xue $\mathbb{D}^{1},{ }^{1,2}$ Lin Cheng $\left(\mathbb{D},{ }^{1}\right.$ Ping Lin, ${ }^{3}$ Jing An, ${ }^{2}$ and Hongzhi Guan ${ }^{2,4}$ \\ ${ }^{1}$ School of Transportation, Southeast University, Nanjing 211102, China \\ ${ }^{2}$ College of Transportation and Logistics, East China JiaoTong University, Nanchang 330013, China \\ ${ }^{3}$ Wuhan Hengshuntong Survey and Design Co., Ltd., Wuhan 430050, China \\ ${ }^{4}$ College of Architecture and Civil Engineering, Beijing University of Technology, Beijing 100124, China \\ Correspondence should be addressed to Yunqiang Xue; xueyunqiang@ecjtu.edu.cn and Lin Cheng; gist@seu.edu.cn
}

Received 21 May 2020; Revised 12 August 2020; Accepted 20 September 2020; Published 7 October 2020

Academic Editor: Indrajit Ghosh

Copyright (c) 2020 Yunqiang Xue et al. This is an open access article distributed under the Creative Commons Attribution License, which permits unrestricted use, distribution, and reproduction in any medium, provided the original work is properly cited.

\begin{abstract}
For travelers who inevitably use motor vehicles, in the case of limited parking spaces, reserving parking spaces in destination in advance helps reduce the time and emissions of searching for parking spaces and alleviate road traffic pressure. From the perspective of bounded rationality, this paper comprehensively considers the impact of traveler's personal attributes and behavioral characteristics on parking reservations. The data processing analysis shows that the traveler's age, gender, monthly income, and other characteristics have a certain impact on the parking reservation choice behavior. Reservation price is the key factor affecting the parking reservation policy. Travelers show different value perceptions of the reserved price of parking spaces, and this process has been verified to be roughly the same as the prospect theoretical model. As the reference point for highest reservation price becomes larger, travelers tend to choose to pay less than the ideal reservation price and become more sensitive to losses. It can be found from the model functions and survey data that the ideal reserved parking space price in the survey area is 5 yuan per hour which equals the normal parking fee, and the ideal parking reservation time is less than 2 hours. The research results provide a basis for formulating reasonable parking reservation schemes and parking policies.
\end{abstract}

\section{Introduction}

With the development of China's economy and society, the rapid increase in the number of urban motor vehicles has caused serious imbalances in the supply and demand of urban parking facilities, and the difficulty of driving and parking has become increasingly serious, which seriously affects urban road capacity and sustainable urban development [1]. Many cities have little experience with parking management, and some ineffective management structure leads to chaotic parking situations which increase air pollution, cause road congestion, and decrease the economic and social efficiency [2]. In the view of the current driving and parking problems, on the one hand, additional parking spaces are built to provide more berths [3]. However, this measure is difficult to realize and sustain due to the limitation in land resources and capital. On the other hand, the allocation mechanisms of parking resources, such as parking reservation, shared parking, and parking charge, are increasingly being favored by managers [3].

By changing the charging price of parking spaces to induce vehicle users to switch to public transportation, easing road traffic congestion is a common measure in traffic demand management [4]. However, many citizens still prefer to use private cars [5]. We have to face the fact that public transportation is usually limited as far as operating hours, service frequency, and service areas. A private car can provide greater flexibility and more comfortable travel service at any time. Additionally, a private car may be a better choice for the residents who do not live within walking distance of bus or subway stations [5]. For commuters who inevitably need to travel by car, they often set off 
early to find parking spaces in order to avoid illegal parking $[1,6-8]$. The problem is that parking spaces are limited, and the time window for early departure is also limited. It is inevitable that there may not be additional parking spaces for early departures. To overcome the parking problem, parking instruments such as shared parking scheme and stereo parking equipment have attracted people's attentions [9]. Stereoparking equipment belongs to a technical policy, it can increase the number of parking spaces per unit area, and therefore it has obvious significance in the short term in easing the problem of parking difficulties. The relatively high maintenance costs and long return cycles for builders and investors have hindered the development of stereo parking equipment. In comparison, shared parking scheme is more attractive to alleviate parking problem [9]. Parking sharing is suitable near the residential compound, because many residents drive out for work during daytime, and the temporarily vacant parking spaces can be utilized to meet other drivers' parking demand who work nearby or come for some activities such as shopping [9-11].

However, in nonresidential areas, there may not be additional parking spaces for sharing. In the areas with limited parking resources and no shared parking spaces, parking reservations are necessary and important for travelers who have to use a car [3]. Drivers usually cruise for an available parking space in urban areas where parking spaces are limited; the cruising process takes significant time and can result in fuel consumption, damaging emissions, and even accidents [12-15]. Shoup found that about one-third of the traffic congestion in road networks is created by cars cruising for parking lots [12], and about $8 \mathrm{~min}$ is spent on average in U.S. cities in finding an available parking space [16]. 63 million miles are needed in Chicago every year for vehicle users to find a vacant parking space; the process generates 48,000 tons of $\mathrm{CO}^{2}$ to the environment [17]. Tsai and Chu also evaluated the parking reservation scheme in urban areas from the environmental perspective [15]. Kaspi et al. studied parking reservation policies for vehicle sharing systems; the effectiveness of the complete parking reservation policy and suggested that parking space reservation policies should be adopted in practice [18]. Mei et al. found that parking reservation is an effective measure in most cities of China to manage parking spaces if the local parking fee is low and hard to increase [3]. The reservation scheme brings an improvement in parking search time between 6 and 13\% [19].

Actually, travelers' choice behaviors are influenced by many factors such as personal characteristics and perceived limitations of life; parking behavior is bounded rational $[1,20]$. In order to describe the travelers' bounded rationality characteristics, the travel choice behavior is modeled according to a satisfaction utility criterion rather than a maximum utility criterion of the expected theory [21]. Soto et al. proposed a hybrid discrete choice model to describe parking choice behavior and study the influence of a positive car care attitude and a risk-averse attitude on parking behavior [22]. Prospect theory, regret theory, and expected utility theory are commonly used to model choice behavior, while the expected utility theory supposes the choice- decision makers are complete rational, resulting in the inconsistency between actual life and theoretical results. In the expected utility theory, the utility of a choice consists of two parts: a fixed item and a random item. The random term of utility represents the deviation between the unobserved utility and the true value. This can reduce the deviation between the predicted value of the expected utility model and the true value to a certain extent. However, the expected utility theory assumes that the decision maker is completely rational, and the decision maker will always choose an option with the maximum utility. In fact, sometimes decision makers did not choose the most optimization option, but chose a satisfactory option, which reflects the bounded rationality of decision makers [21]. de Moraes Ramos et al. compared the above three theories and found that prospect theory is more suitable than both expected utility theory and the regret theory for modeling travel choice behavior [23]. Liu et al. examined the efficiencies of parking reservation schemes considering expiration times. However, the bounded rationality of car travelers is not discussed [24]. Several studies used prospect theory to model departure time choice behavior of car travelers considering bounded rational characteristics [1]. The similar researches are seldom in parking reservation behavior under bounded rationality.

In summary, there is plenty of researches focus on parking problems or bounded rational choice behaviors. However, these studies do not involve the parking reservation choice behavior under bounded rational perspective. Therefore, when we study the parking reservation choice behavior, the bounded rationality of vehicle travelers should be considered so as to guide the parking reservation strategies more reasonable and scientific. It is also a question worth considering whether it is possible to benefit both the parking lot user and the parking lot manager in the case of a limited public parking space supply by appropriately preserving the destination parking space in advance. If the reserved time is too long, it will result in the increase of travelers' cost. If the reserved time is too short, it may cause the traveler to fail to arrive at the parking space in time. Different travelers have different references or even present bounded rational behaviors when balancing the reservation time and cost. Therefore, to solve the parking problems, it is necessary to grasp the bounded rational behavior of travelers choosing to reserve a parking space when there are insufficient public parking spaces and to formulate a reasonable reservation scheme and parking policy based on this behavior.

In this study, the parking reservation choice behavior under bounded rational perspective is involved. The prospect theory is applied to investigate, analyze, and model the parking reservation choice behavior of car travelers, and the appropriate reservation fee, time, and corresponding scheme are proposed. The research results can provide theoretical basis and guidance for the parking reservation policies, help to promote the sustainable development of urban transportation, alleviate traffic congestion, and decrease pollutant emissions in parking process. The research structure is arranged as follows: Section 2 is the research methodology; Section 3 is the analysis of influencing factors of the parking 
reservation behavior; Section 4 is RP (revealed-preference) and SP (stated-preference) survey and data analysis; Section 5 is prospect theory model calibration and discussion, and Section 6 is conclusion.

\section{Research Methodology}

Stated preference (SP) survey is carried out to collect the parking reservation behaviour data. According to the SP survey data, a travelers' parking reservation model is established based on prospect theory. In this way, the car traveler's parking reservation payment reference value is obtained, and the policy design and evaluation analysis are conducted to provide theoretical support and suggestions for the formulation of a parking reservation scheme.

\subsection{Prospect Theory}

2.1.1. Characteristics of Prospect Theory. Prospect theory was proposed by Kahneman and Tversky [25]. They revised the theory of maximum subjective expected utility to derive the "prospect theory" [26]. Prospect theory addresses risky choices such as whether or not to travel by car and whether or not to use parking reservation scheme $[8,27]$.

Prospect theory is a model of descriptive paradigm about decision-making behavior. It divides risk decision-making into two processes: editing and evaluation. In the editing process, people collect information through models, frames, reference points, etc. In the evaluation process, they rely on the value function and the weight function of subjective probability to make judgments and process information $[8,27]$. The characteristics of prospect theory are as follows: (1) persons are more sensitive to loss than gain; (2) most persons are risk-preferred when facing losses; (3) most persons are risk-averse when facing gains; (4) persons not only value the absolute amount of wealth but also the amount of change in wealth. People evaluate outcomes in terms of gains or losses relative to a reference point; (5) the early decision-making results will affect later attitudes to risk and behavioral decisions. The utility under prospect theory depends on the transformed probability, also known as decision weights, not like the expected utility theory which depends on the original probability. Therefore, individuals are always cautious about the existence of risk factors when faced with it. People's sensitivity to loss and gain are different. In general, the sadness of loss will greatly exceed the happiness that exists when acquiring something.

In the beginning, the prospect theory was used to predict the results of economic decision-making [26-28]. After many years of research and development, people gradually applied the prospect theory to major research fields. The outstanding research field has also been validated for the adaptability and effectiveness of traffic behavior decisionmaking $[1,6,8,20,29-32]$. Prospect theory believes that people usually do not consider the problem from the perspective of the expected amount of value but from the maximum expected utility value to consider how much benefit this decision can bring to them. This view is the same as people's actual emotional sentiment for decision-making.
Most people's decision-making behavior is generally based on the gaps brought by their own benefits, rather than the absolute value we often think.

2.1.2. Model Framework of Prospect Theory. The loss and gain of parking reservation behaviour in the view of bounded rationality are obtained by comparison with the reference point. With the growth of time, a large number of experimental investigations and studies have fully shown the complexity of human decision-making behaviours. For the second stage of evaluation and decision-making, people will process the information collected in the first stage to make it more concise and clear and finally choose the decisionmaking behavior according to their own perceptions, resulting in different people's decisions on the same thing.

Prospect theory assumes that there are two functions to measure the value of decision-making behavior: the value function $v(x)$ and the decision weight function $\pi(p)$ $[26,28]$. These two functions replace the original expected utility function and subjective probability function model. These two function models indicate that the decisionmaker's decision is influenced by two processes, on the one hand, the value function (that is, the subjective value), and on the other hand, the decision weight function (that is, the decision-maker's influence probabilistic perception effects). There are several differences between the two theoretical models of value function $v(x)$ and decision weight function $\pi(p)$ :

First, the value function model used by prospect theory replaces the utility function of expected utility theory. Generally, people think that the origin of the coordinate is the reference point, the right side of the $x$ coordinate axis is the revenue area, and the value of the value function is greater than 0 ; the left side of the $x$ coordinate axis is the loss area, and the function value is less than 0 . Through a large number of experiments, it is shown that, in real life, people are more concerned about the relative value of loss and gain relative to the reference point than the absolute value. The form of the value function presents an S-shape (Figure 1). Many researchers say $[26,28,29,31-34]$ that it is a convex function of loss and a concave function of profit. This means that the decision maker in the loss range behaves as a hobby risk, and the decision maker in the profit range shows risk aversion. The definition of the value function is on the loss and gain relative to a reference point, which determines the specific situation of the investor's relative loss and gain, and the determination of the reference point is usually based on individual's preference. The slope of the curve in the profit area is smaller than the slope of the curve in the loss area. This means that under the same value, the sensitivity of decision makers to loss is greater than the sensitivity to income. The value function is expressed as follows:

$$
v(x)=\left\{\begin{array}{l}
a x^{\alpha}(x>0, a>0, \alpha>0), \\
-b x^{\beta}(x<0, b>0, \beta>0) .
\end{array}\right.
$$

Second, the decision weight function model used by prospect theory replaces the original probability function 


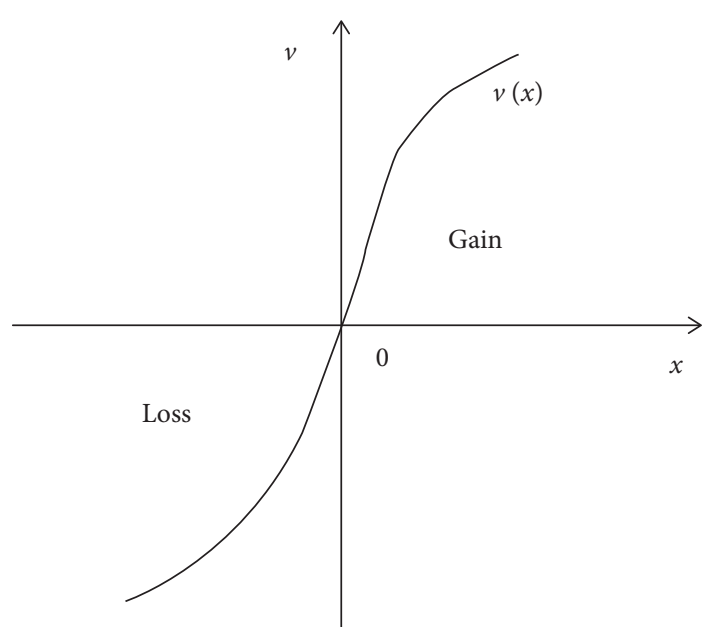

Figure 1: Value function $v(x)$.

based on the expected utility theory. Its meaning does not fully reflect the objective probability of an event. Some scholars $[26,28,29,31-34]$ say that the decision weight function used by the prospect theory refers to the subjective probability of the objective numerical values of the event probability after subjective judgment. The decision weight function has two main characteristics (Figure 2): (1) there is a clear difference between the objective probability and the subjective probability of an event. It mainly means that people tend to overestimate low-probability events and underestimate medium-high-probability events. The performance of probabilistic dynamic changes is relatively insensitive. (2) For very low-probability events, the weight value is 0 , and for very high probability events, the weight value is 1 . The decision weight function is not a probability function, so it does not follow the laws and theorems of probability. It shows a nonlinear function that rises monotonously, indicating that the probability of accidental occurrence of an impossible event is ignored and the metric is standardized.

Prospect theory believes that the total value of the edited decision events under uncertain conditions can be expressed by $V$, also known as the prospect value. And, $V$ can be expressed by the product of the value function $v(x)$ and the decision weight function $\pi(p)$. For the decision result of an event, it is divided into two parts: gain $x_{1}$ and loss $x_{2}$; then the final prospect value of this event is

$$
\pi(p)=v\left(x_{1}\right) \pi\left(p_{1}\right)+v\left(x_{2}\right) \pi\left(p_{2}\right) .
$$

\subsection{Behavior Model of Parking Reservation Choice Based on Prospect Theory}

2.2.1. Choice Behavior of Parking Reservation. Car travelers usually choose reserved parking spaces based on the prediction information provided by the real-time information system and personal habits in the daily travel process. Travelers' decision-making behavior is usually influenced by their own personality preferences, the situation they are in, the parking lot environment, and the length of time they

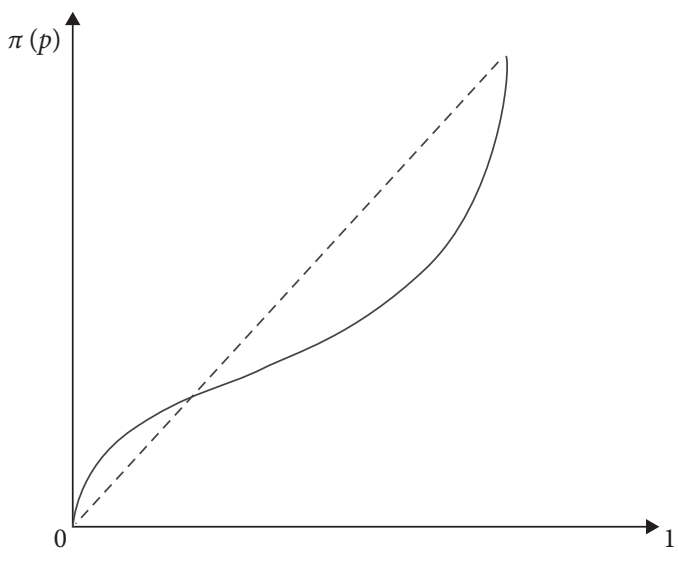

Figure 2: Decision weight function $\pi(p)$.

park their vehicles. Therefore, due to different personalities, hobbies, feelings, and ways of thinking of different travelers, there are also differences in the prices of reserved options for acceptable parking spaces. It changes according to the change of the individual's situation; therefore, it is not a fixed value.

Due to the uncertainties and mobility of the urban road network and traffic, travelers' decision-making psychology when choosing parking behaviors is the same as the basic view of the prospect theory model. Therefore, this article adopts the perspective of bounded rationality to analyze the traveler's choice of reserved parking spaces in public parking. This article mainly considers whether travelers are willing to pay a certain amount of money to reserve parking spaces in advance when parking spaces in the parking lot are in short supply, so as to get a parking space at a suitable price.

\subsubsection{Price Reference Points of Parking Reservation.} According to the prospect theory, there are two reference points for the price of reserved parking spaces for travelers, one reference point is the lowest price willing to pay the reserved price, and the other one is the highest price willing to pay. When the traveler is willing to pay the reserved price between the lowest and the highest prices, the traveler thinks that paying a certain amount of reserved parking space in advance avoids illegal parking fines or delays, etc., so he or she feels the gains. When the willing-to-pay price exceeds the maximum price, it is in an unacceptable period, and travelers feel lost at this time. Between the highest and lowest reserved prices, travelers are most satisfied with the choice of reserved parking spaces in advance at the reserved price that people are most willing to pay, and the corresponding prospect value is the largest. According to the data of our actual survey, we will analyze the travelers' characteristics in real life and establish a prospect theory model with the reservation price as the parameter. The value function diagram is shown in Figure 3.

In Figure 3, $x_{a}$ is the lowest reservation price a car traveler willing to pay, it can take the value 0 as the lowest reservation fee, that is, the parking reservation is free; $x_{b}$ is the optimal reservation price; $x_{c}$ is the highest reservation 


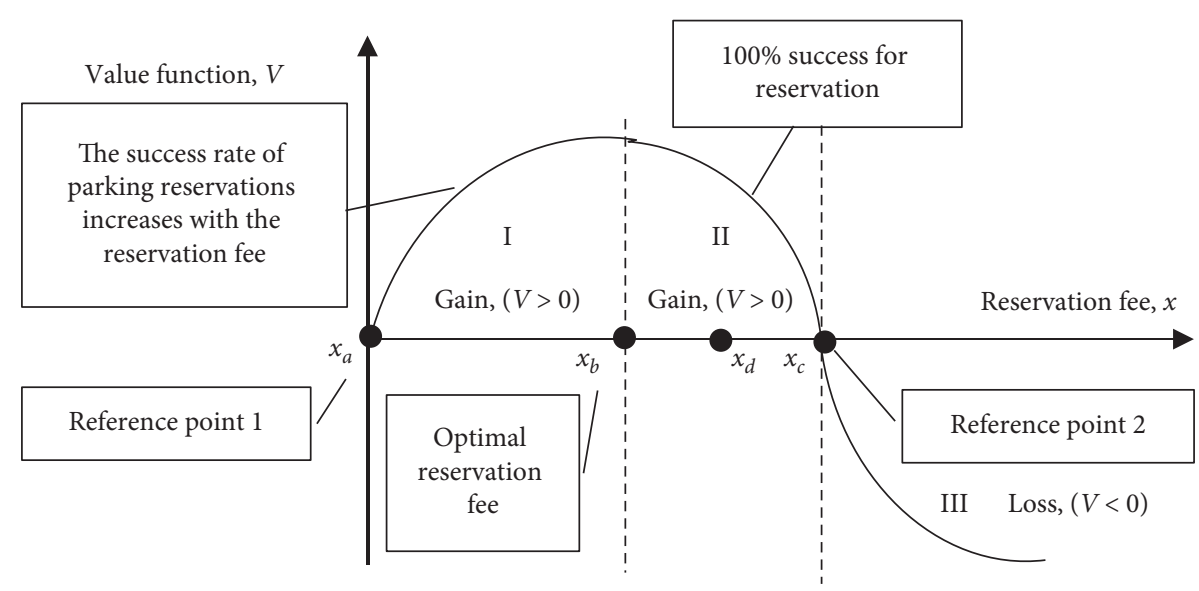

FIgURE 3: Value function of parking reservation fee choice.

price a car commuter willing to pay; $x_{d}$ is the actually paid reservation fee.

It can be seen from Figure 3 that $x_{a}$ and $x_{c}$ are two reference points, $x_{b}$ is the traveler's most expected reservation prices that just happened to be successfully reserved and also a pseudoreference point. When the reservation fee of travelers willing to pay is less than $x_{a}$, the parking lot manager is unwilling to carry out the activity of reserving parking spaces, so this situation is not considered. When the amount that the traveler is willing to pay is larger than $x_{c}\left(x_{d}>x_{c}\right)$, the traveler feels that the price is too high and is not worth the cost (not cost-effective). At this time, the value function is negative, and the values are less than 0 . The traveler will adjust the reservation fee in the next choice until the prospect value is positive. When the price of the reserved parking space is between $x_{a}$ and $x_{c}\left(x_{a}<x_{d}<x_{c}\right)$, the traveler thinks that he can reserve a parking space in advance and has a sense of gain. At this time, the value function is positive, and the values are greater than 0 . Among them, areas I and II are concave and area III is convex, which also shows that the prospect theory is a concave function of gain and a convex function of loss. Areas I and II are symmetrical or asymmetrical depending on the value of $x_{b}$.

When the price of the reserved parking space is between $x_{a}$ and $x_{b}\left(x_{a}<x_{d}<x_{b}\right)$, as the reserved price rises, the probability of successful reserved parking spaces increases. Due to the limited parking resources, there is a bidding relationship among travelers, and those with higher prices are more likely to reserve parking spaces successfully. Therefore, as the parking reservation success rate continues to increase in the first area, the traveler's sense of gain increases. In area II $\left(x_{b}<x_{d}<x_{c}\right)$, the probability of successful reserved parking is $100 \%$. At this time, as the price continues to raise, the traveler's gain decreases; when the maximum value of the reserved price $x_{b}$ is exceeded, the traveler feels a loss. Intuitively, the most expected reservation price for travelers is the price that happens to be $100 \%$ successful for reserving a parking space. For the parking lot manager, it is hoped that the higher the reservation price, the better. However, when the reservation price is too high, the traveler's gain from parking reservations decreases and the enthusiasm for using parking reservations decreases.

In order to illustrate the distribution of the value function of parking reservation fee shown in Figure 3, it is necessary to investigate and obtain SP survey data to verify the distribution curve of the value function.

2.2.3. Theoretical Model of Parking Reservation Based on Prospect Theory. According to the previous analysis of prospect theory and value function, the value function model is a segmentation model containing two reference points. Considering the different characteristics of different people's decision-making behavior on the same thing, the model formula of value function is expressed as follows. $V(x)$ is the function value of the gain or loss that the traveler feels for the reserved parking space. When the gain is felt, $V(x)>0$; when the loss is felt, $V(x)<0$. $V_{1}(x), V_{2}(x)$, and $V_{3}(x)$ refer to the three partitions of the above value function diagram:

$$
V(x)= \begin{cases}V_{1}(x)=\alpha_{1}\left(x_{d}-x_{a}\right)^{\lambda_{1}}+\varepsilon_{1}, & 0 \leq x_{a}<x_{d} \leq x_{b}, \\ V_{2}(x)=\alpha_{2}\left(x_{c}-x_{d}\right)^{\lambda_{2}}+\varepsilon_{2}, & x_{b}<x_{d} \leq x_{c}, \\ V_{3}(x)=\alpha_{3}\left(x_{d}-x_{c}\right)^{\lambda_{3}}+\varepsilon_{3}, & x_{d}>x_{c},\end{cases}
$$

where $\alpha_{i}(i=1,2,3)$ are the coefficients of the traveler's value weighting function for losses and gains in the three corresponding areas. In the income area, the greater the absolute value, the more sensitive the traveler is to the benefits of reserved parking spaces. The greater the absolute value in the loss area, indicating that the traveler is the higher sensitive to the loss. And, in the income area, $\alpha_{i}>0$; in the loss area, $\alpha_{i}<0 . \lambda_{i}(i=1,2,3)$ are risk pursuit coefficients, which lies in a range of $(0,1)$, and the larger value of $\lambda_{i}(i=1,2,3)$, the more risk is pursued. $\varepsilon_{i}(i=1,2,3)$ are the travelers' perception errors of decision-making behavior when they use parking reservation; some researchers suppose the travelers' perception errors obey double exponential distribution, and the expected value of $\varepsilon_{i}(i=$ $1,2,3)$ is zero [1]. In this research, we suppose the errors 
$\varepsilon_{i}(i=1,2,3)$ satisfy the single exponential distribution, and the expected value of error $\varepsilon$ is also zero. That is, after multiple choices, the traveler's decision error gradually decreases, and the decision gradually returns from bounded rationality to rationality.

According to formula (3), if the value function $v_{i}(t)>0$ when the parking reservation fee lays in the area I or the area II, the traveler's travel value is profitable. If the traveler is satisfied with the parking reservation, he or she may not change the parking behavior in the next decision. If the traveler wants to continue to increase the prospect value, he can adjust the paid parking fee toward $x_{b}$. Its probability is expressed as follows:

$$
\begin{aligned}
& P\left(V_{1}>0\right)=1-\exp \left(-\left(\alpha_{1}\left(x_{d}-x_{a}\right)^{\lambda_{1}}+\varepsilon_{1}\right)\right) \\
& P\left(V_{2}>0\right)=1-\exp \left(-\left(\alpha_{2}\left(x_{c}-x_{d}\right)^{\lambda_{2}}+\varepsilon_{2}\right)\right) .
\end{aligned}
$$

Similarly, when the parking reservation fee is in the area III, the value function is negative. The parking lot manager has to adjust the parking reservation fee. If it is not adjusted, because the price is too high, travelers do not use parking reservations, which will affect the revenue of parking managers. The probability is expressed as follows:

$$
P\left(V_{3}<0\right)=1-\exp \left(-\left(\alpha_{3}\left(x_{d}-x_{c}\right)^{\lambda_{3}}+\varepsilon_{3}\right)\right) .
$$
follows:

Then, the probability density function of each area is as

$$
\begin{gathered}
f\left(x_{1}\right)=\alpha_{1} \exp \left(-\alpha_{1}\left(x_{d}-x_{a}\right)^{\lambda_{1}}+\varepsilon_{1}\right), \\
f x_{2}\left(x_{2}\right)=\alpha_{2} \exp \left(-\alpha_{2}\left(x_{c}-x_{d}\right)^{\lambda_{2}}+\varepsilon_{2}\right), \\
f\left(x_{3}\right)=\alpha_{3} \exp \left(-\alpha_{3}\left(x_{d}-x_{c}\right)^{\lambda_{3}}+\varepsilon_{3}\right) .
\end{gathered}
$$

\section{Factors Affecting the Choice Behavior of Parking Reservation}

Parking fee and parking search time are the major factors that significantly affect commuters' travel behaviors [24]. In addition to the above factors, a positive car care (maintenance) and a risk-averse attitude are also determinants for parking choice [22]. Research results show that personal characteristics also affect travel behaviors $[1,8,9,11,21,22,25,30]$. This paper mainly considers the personal characteristics and parking characteristics of behavioral decision makers and analyzes the bounded rationality of decision makers and willingness to pay the cost to obtain reserved parking spaces.

3.1. Individual Attributes Influencing Parking Choice Behaviors. Travelers' personal factors generally include age, gender, hobbies, feelings, and monthly income.

Car ownership preferences of different age cohorts are changing over time [34]. Young commuters have a strong sense of adventure, and this kind of crowd is usually more receptive to new things. The younger the age, the greater the chance of choosing to accept reserved parking spaces, and the greater the possibility of considering to accept this new method. The older the age, the more factors are considered when reserving and selecting parking spaces. This kind of crowd usually has a strong conservative mind when reserving and selecting parking spaces.

Generally, male travelers choose parking spaces more boldly and aggressively than female travelers, and they are more adventurous. Men's choice is far less than women's choice. Female travelers generally consider more factors when they reserve parking spaces. In the case of insufficient parking spaces in the destination, the parking reservation choice behavior of men is usually more adventurous than women.

Travelers' hobbies and feelings are generally affected by their family environment, living environment, working environment, personality, etc., and there are great differences in personal hobbies and feelings. Different travelers will make different judgments according to their hobbies and feelings about parking spaces and then choose whether to reserve parking spaces.

If the traveler is a person with a relatively high monthly income, then he will be less concerned about paying a certain amount of fees than a person with a low monthly income. When choosing whether to reserve parking spaces, highincome people are also more likely to accept this behavior of reserving parking spaces in advance.

3.2. Reservation Fee. The reserved fee refers to the price of a parking space reserved for a period of time. The longer the parking space is reserved, the higher the fee. If the reserved time for a reservation parking space is too short, the traveler may not arrive at the reserved parking space in time. Therefore, travelers determine the reserved time for reserved parking spaces based on their travel status. Generally speaking, when the reserved fee is high, people are less willing to pay a certain amount of money to choose reserved parking spaces. When the reserved fee is relatively moderate or relatively low, it is easier for people to accept the reserved parking spaces.

3.3. Parking Environment. The environmental factors of the parking lot mainly include the road environment, the parking space environment, and the safety of vehicle placement.

Travelers tend to choose parking berths with better road environment, excellent parking berth environment, and higher safety performance for vehicle placement. Some travelers may choose to reserve parking spaces in order to choose more satisfactory parking spaces. The safety of vehicle placement is particularly important at night. Large parking lots are generally equipped with monitoring equipment to ensure the safety of vehicle parking. Generally, people think that the closer the parking space is to the monitoring device, the safer it is. However, the number of such parking spaces is limited, so the environment of the parking lot has a certain impact on the behavior of travelers to reserve parking spaces. 
3.4. Travel Characteristics. The travel status mainly includes two aspects: the effective parking space status and the parking time status.

The effective parking space status mainly refers to the number of remaining parking spaces. The more parking spaces left, the more space for travelers to reserve and select parking spaces. Usually, in this case, the traveler can consider more parking spaces and then choose a satisfactory parking space. When the number of effective parking spaces is small, the traveler can only choose one of the remaining parking spaces; usually in this case, the uncertainty of the traveler's reservation and selection of parking spaces is small. People are more willing to pay a certain amount of money in advance to reserve parking spaces when the number of available parking spaces is insufficient. When parking spaces are sufficient, travelers can find parking spaces at any time without having to reserve parking spaces in advance. At this time, people do not have the strong desire to choose reserved parking spaces. Therefore, if it is possible to establish a theoretical model of the prospect of parking demand, analyze the reference value of the berth reservation cost of commuter travelers, and propose a parking berth reservation option for parking lot; it is very helpful to improve the efficiency of parking lot.

The parking time situation mainly refers to the sufficient time for commuters to park their vehicles. If the traveler's parking time is very tight due to work and other reasons; in this case, the traveler is generally more willing to reserve parking spaces. Conversely, travelers are less likely to choose to reserve berths.

3.5. Parking Reservation Policy. The policy enforcement of public parking spaces in parking lots also affects travelers' choice of reserved parking spaces. When the enforcement of this parking lot policy is strong (such as illegal parking fines are relatively large), people are generally willing to accept parking spaces reserved in advance to minimize their losses. When the implementation of the parking lot is weak, people's desire to reserve parking spaces is not so strong. For example, in daily life, if car travelers reserve parking spaces in advance by paying a certain amount of money, then there is no process of "searching for parking spaces" after the travelers arrive at the parking spaces. Travelers do not need to face the situation that there are no parking spaces that result in parking fines and spend a lot of time to find parking spaces and delay work. At this time, the traveler feels the benefit by avoiding the bad things that may occur. If the traveler does not reserve a parking space in advance, the traveler needs to choose a parking space after arriving at the parking lot. If the parking lot has no parking spaces and will be fined for illegal parking, the traveler may feel the loss.

\section{Survey and Data Analysis}

4.1. Survey Design. The RP\&SP survey was conducted from April $9^{\text {th }}$ to April $20^{\text {th }}, 2019$. A total of 175 questionnaires were collected in this survey, including 46 invalid questionnaires and 129 valid questionnaires. A pilot survey with a sample size of 10 was also conducted before the RP\&SP survey, and the content of the questionnaire was adjusted based on the feedback from the pilot survey. Under the hypothetical situation, the ideal reserved parking space price is collected through the questionnaire survey. The survey includes the traveler's personal attributes (gender, age, income, hobbies, and feelings), the level of reserved fees, parking policies, parking environment, and other factors. The detailed survey questions and the statistic results of the survey data are listed in Table 1. The first three questions belong to RP (revealed preference) survey, and the rest questions belong to SP (stated preference) survey. The most significant difference between SP survey and RP survey is that the RP survey obtains objective and realistic data, while the SP survey is to obtain the willing choices made by the respondents under hypothetical conditions.

This study conducted a questionnaire survey at the Hengmao International City Commercial Complex in Nanchang, China (Figure 4). The survey area is close to Bayi Square, there are many commercial areas and office buildings, and there are many people and vehicles. The parking space is in short supply, and the normal parking fee is 5 yuan/hour. The illegal parking phenomenon is serious. As the number of motor vehicles continues to grow, the difficulty of parking will become more serious. Therefore, it is necessary to seek the reserved price of parking spaces to meet the needs of people traveling by cars under the bounded rational perspective.

Based on the survey data, we analyze the choice and reservation behavior of public parking spaces under bounded rationality. Because respondents pay more attention to personal privacy, on-site questionnaire surveys are not so easy. Fortunately, the disaggregated modeling analysis based on the RP \& SP survey does not require a large sample size. Studies [35] have shown that, if the sampling is reasonable, about 200 survey samples are generally representative. The sample size of this article is based on the above research. By solving the gradient vector and Hessian matrix of unknown parameters and then using the NR (NewtonRaphson) method or the DGP (DavidonFetcherPowell) method, the sample size that meets the accuracy requirements can be obtained after multiple iterations [35]. The ratio of male to female respondents is 1.05:1 (66 male respondents and 63 female respondents, see Table 1), which is close to $1: 1$ and consistent with the statistical characteristics of small samples [1].

\subsection{Survey Data Analysis}

4.2.1. Personal Attribute Analysis. As seen from Table 1, the ages of the respondents are mainly between 18 and 45 years old, especially young people and middle-aged commuters. This is in line with the age characteristics of motor vehicle drivers in China. 117 travelers were aged 18-45 years old, accounting for $90.7 \%$ of the total respondents, which indicates that the travelers in the region are mainly young and middle-aged people. 
TABLE 1: Survey statistics of the respondents' personal characteristics and choice behaviors.

\begin{tabular}{|c|c|c|c|c|}
\hline Serial number & Survey content & Options & Number of respondents & Percentage (\%) \\
\hline \multirow{2}{*}{1} & \multirow{2}{*}{ Gender } & Male & 66 & 51.16 \\
\hline & & Female & 63 & 48.84 \\
\hline \multirow{4}{*}{2} & \multirow{4}{*}{ Age } & $18-25$ & 25 & 19.38 \\
\hline & & $26-35$ & 55 & 42.64 \\
\hline & & $36-45$ & 37 & 28.68 \\
\hline & & $>45$ & 12 & 9.30 \\
\hline \multirow{5}{*}{3} & \multirow{5}{*}{ Monthly income (yuan) } & $<3000$ & 43 & 33.33 \\
\hline & & $3000-4999$ & 64 & 49.61 \\
\hline & & 5000-6999 & 13 & 10.08 \\
\hline & & $7000-10000$ & 4 & 3.10 \\
\hline & & $>10000$ & 5 & 3.88 \\
\hline \multirow{4}{*}{4} & \multirow{4}{*}{ Emotional factors (multiple choice) } & Mood & 70 & 54.46 \\
\hline & & Feelings & 55 & 42.88 \\
\hline & & Hobbies & 45 & 34.82 \\
\hline & & None & 40 & 31.25 \\
\hline \multirow{2}{*}{5} & \multirow{2}{*}{ Parking environment affect choice } & Yes & 114 & 88.37 \\
\hline & & No & 15 & 11.63 \\
\hline \multirow{2}{*}{6} & \multirow{2}{*}{ Number of parking spaces affect choice } & Yes & 112 & 86.82 \\
\hline & & No & 17 & 13.18 \\
\hline \multirow{2}{*}{7} & \multirow{2}{*}{ Parking time affect choice } & Yes & 110 & 85.27 \\
\hline & & No & 19 & 14.73 \\
\hline \multirow{2}{*}{8} & \multirow{2}{*}{ Consider reservation fee most } & Yes & 106 & 82.17 \\
\hline & & No & 23 & 17.83 \\
\hline \multirow{2}{*}{9} & \multirow{2}{*}{ Illegal parking fines affect choice } & Yes & 97 & 75.19 \\
\hline & & No & 32 & 24.81 \\
\hline \multirow{2}{*}{10} & \multirow{2}{*}{ Will you reserve a parking space } & Yes & 105 & 81.40 \\
\hline & & No & 24 & 18.60 \\
\hline 11 & Retention time of reserved parking spaces & Fill in & 129 & - \\
\hline 12 & Acceptable reservation fee (Yuan/hour) & Fill in & 129 & - \\
\hline 13 & Acceptable highest reservation fee & Fill in & 129 & - \\
\hline 14 & Reservation fee for $50 \%$ success & Fill in & 129 & - \\
\hline 15 & Reservation fee for $70 \%$ success & Fill in & 129 & - \\
\hline
\end{tabular}

The majority of the respondents had monthly incomes below 5,000, accounting for $83 \%$, and only $7 \%$ of respondents with monthly income above 7000 . It shows that the respondents' personal monthly income level is in the lower middle level. In the survey, it was found that most people have the option to choose lower than their actual personal monthly income. It is possible that income is a topic that touches privacy, and people are unwilling to disclose their true income to strangers.

The emotional factor is a multiple choice question. As can be seen from Table 1, the three factors of mood, feeling, and hobby are all related to the public parking berth reserved choice behavior. Among them, the influence of mood is the most important influence on the reserved choice behavior. The influence of feelings ranks second, and the influence of hobbies ranks third. Among them, 31.25\% of them are not affected by the emotional factors.

4.2.2. Yes or No Choice Analysis. Questions 5-10 are about whether or not the factors affecting parking reservations. The parking lot environment has a certain influence on the commuter travelers' reserved choice behavior. $88 \%$ of respondents think that the parking lot environment will be related to whether they choose to reserve parking spaces in advance, and $12 \%$ think will not.

Effective parking spaces in parking lots have an impact on travelers' choice of choice. $87 \%$ of travelers think that the status of effective parking spaces in parking lots will be related to their decision-making behavior, and 13\% think they will not.

The length of parking time also has an influence on the reservation behavior. $85 \%$ of the travelers in the survey think that the length of parking time will have an impact on their decisionmaking behavior, while the remaining $15 \%$ think it is not.

Among the respondents, it is believed that the reserved price is related to the behavior of reserved parking. $82 \%$ of travelers think that the reserved price is the primary factor for considering reserved parking spaces.

$81 \%$ of respondents thought that the illegal parking penalty policy would affect travelers' decision to reserve parking spaces, while $19 \%$ thought it would not. It can be seen that most travelers believe that the decision-making behavior of individual reserved parking spaces is related to the parking lot normative policies. Assuming that the parking lot has insufficient parking spaces, the illegal parking is fined 200 yuan and $81 \%$ respondents are willing to pay a certain amount of fees so as to reserve a parking space in advance. 


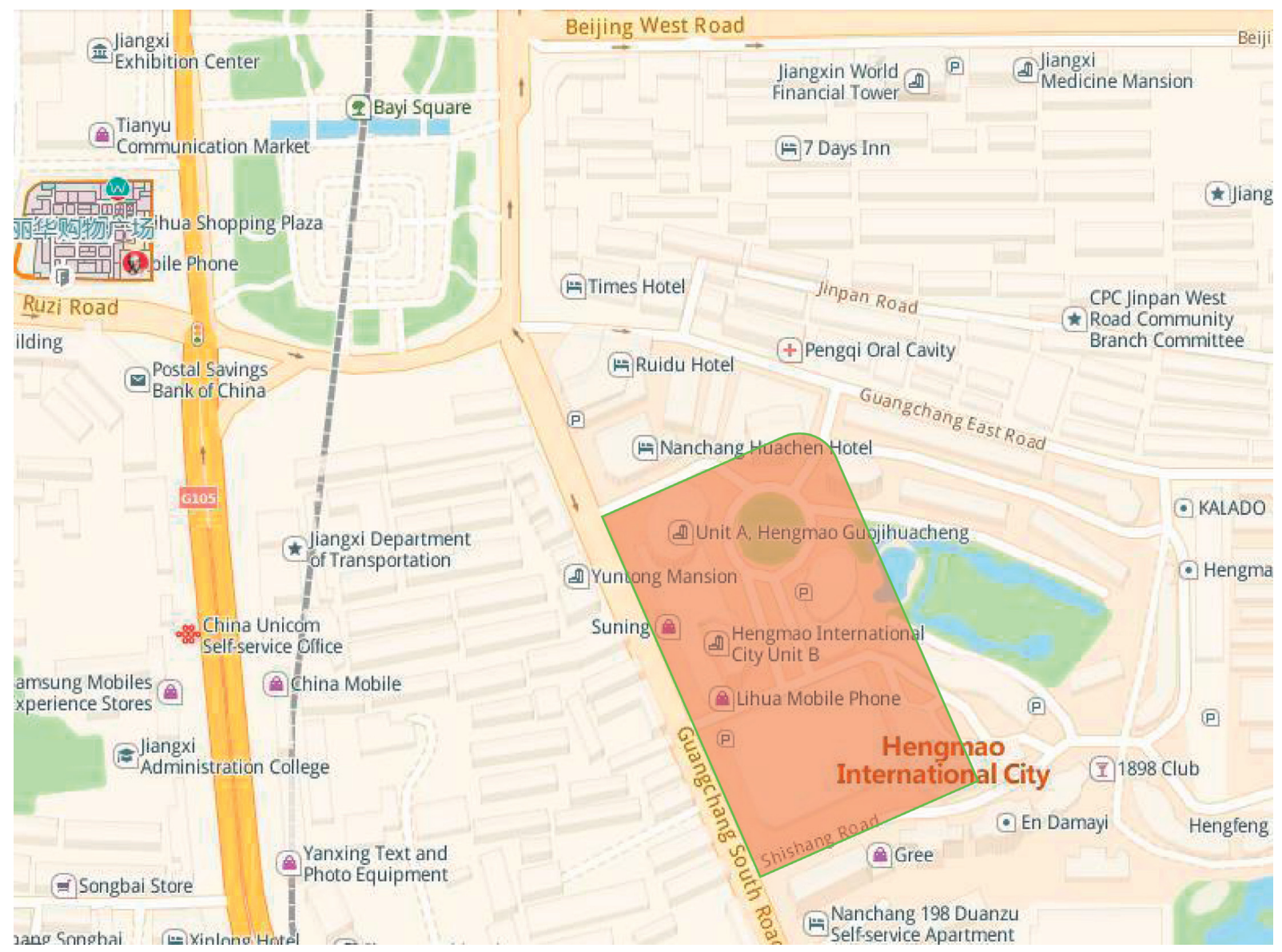

Figure 4: Survey scope.

4.2.3. Reservation Time Analysis. The majority of travelers in the survey hope to reserve 1-4 quarters in advance, accounting for $44.9 \%$. The general trend of travelers' expectation decreases with the increase of the reserved time. Therefore, it can be seen that the ideal reserved time interval for travelers is $1-4$ quarters. The ideal reserve time for $30 \%$ of the respondents is an hour. The next ideal reserve time is 8 quarters, or two hours. According to Figure 5, the maximum number of travelers chooses in the interval of 0-8 quarters. Therefore, it can be suggested that the parking space that can be reserved in advance in this parking lot is not more than two hours.

4.2.4. Reservation Fee Analysis. It can be seen from Figure 6 that people think the most ideal price for reserved parking spaces is 5 yuan/hour (equals the normal parking fee) and that the range of reserved parking prices is between $[5,10]$. The number of respondents in this interval is 98 , and the ratio is $75.97 \%$. It can be seen that if the reserved price of the parking lot is in this range, the traveler is satisfied. Some travelers are willing to bid for 200 yuan per hour to reserve a parking space. He may believe that spending 200 yuan to reserve a parking space can save time and can avoid illegal parking fine of 200 yuan or more. However, more than 10 yuan per hour to reserve parking spaces is still in the minority. The average reserve fee of the respondents is 12.22 yuan/hour.

The highest reserved parking fee for most travelers is 10 yuan/hour (Figure 7). The reserved parking space prices that travelers are willing to pay are mainly concentrated in the interval $[5,12]$, with a total of 89 people, accounting for $69 \%$. Among them, 9, 10, or 11 yuan/hour are the prices most chosen by people, accounting for $38 \%$.

It can be seen from Figure 8 that if there is only $50 \%$ chance of success to reserve a parking space, the reserved price that the traveler is willing to pay is 3 yuan/hour, where $(2,5)$ is the interval that most travelers are willing to pay, the number of respondents is 86 and the proportion is $67 \%$. Of course, some travelers feel that there is only half of the possibility to reserve successfully, but simply do not reserve. There are also 6 such travelers, but this number of respondents is relatively small. If there is a $70 \%$ probability of successfully reserving a parking space, the price that commuter travelers are most willing to pay is 4 yuan/hour, where $(3,7)$ is the interval that travelers are most willing to pay (Figure 9). The statistical number in the above interval is 86 , accounting for $67 \%$.

Figure 10 is a summary chart considering four prices (ideal price, highest price, price at $50 \%$ success, and price at $70 \%$ success) selected by the traveler. The total number of data is $129 * 4=516$. The choice result is concentrated at 5 yuan/hour, which happens to be the normal parking price. 


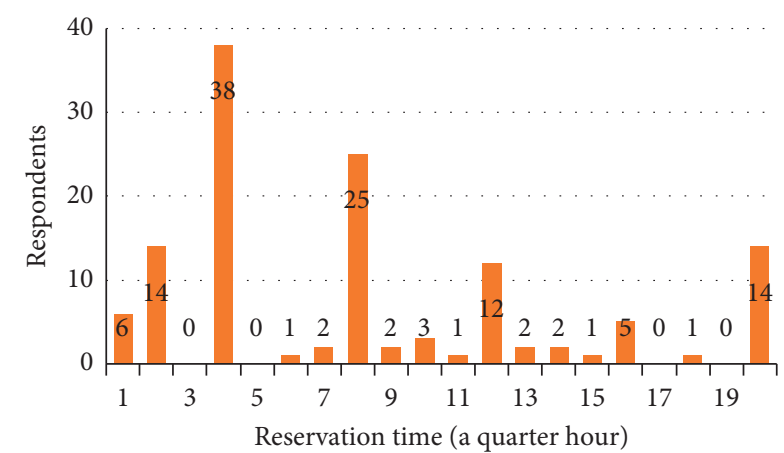

Figure 5: Ideal reservation time.

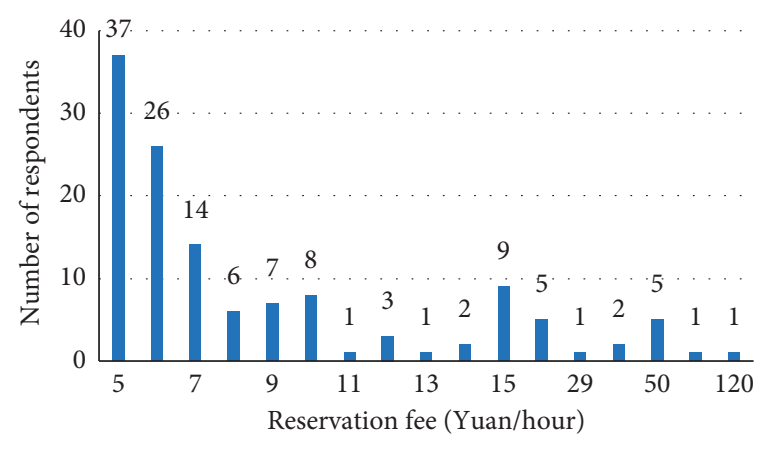

FIgURE 6: Ideal reservation fee.

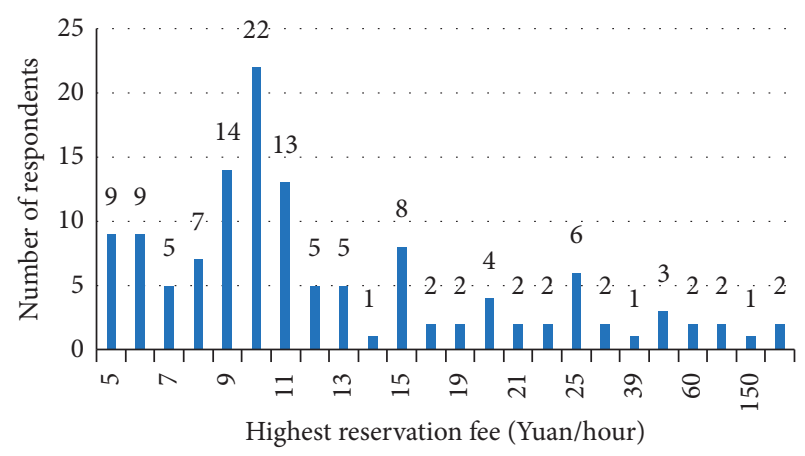

Figure 7: Acceptable highest reservation fee.

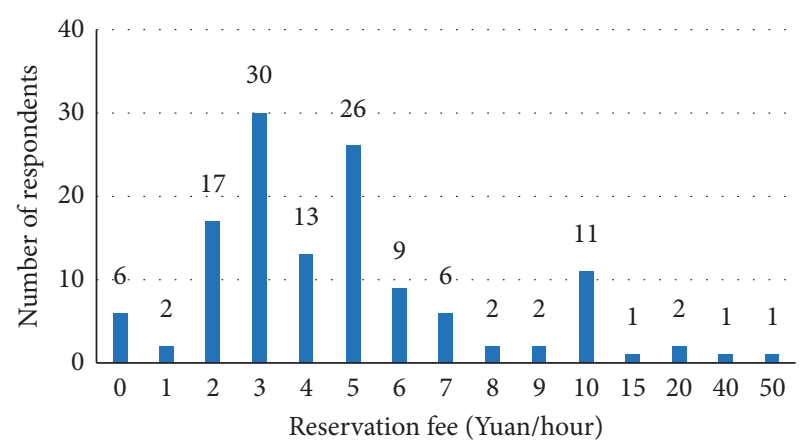

Figure 8: Reservation fee for $50 \%$ success.

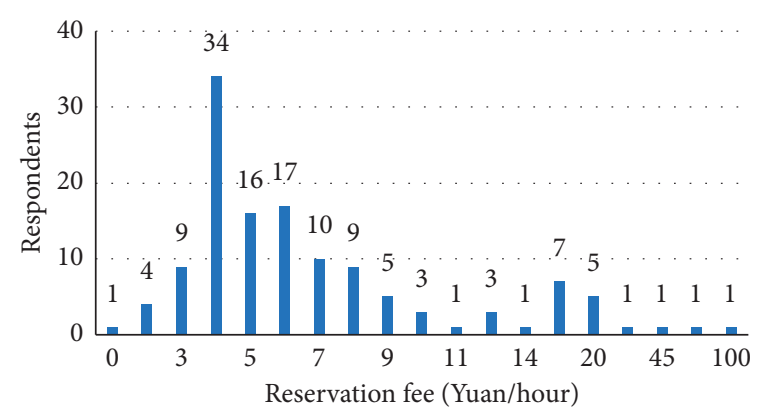

FIgURE 9: Reservation fee for $70 \%$ success.

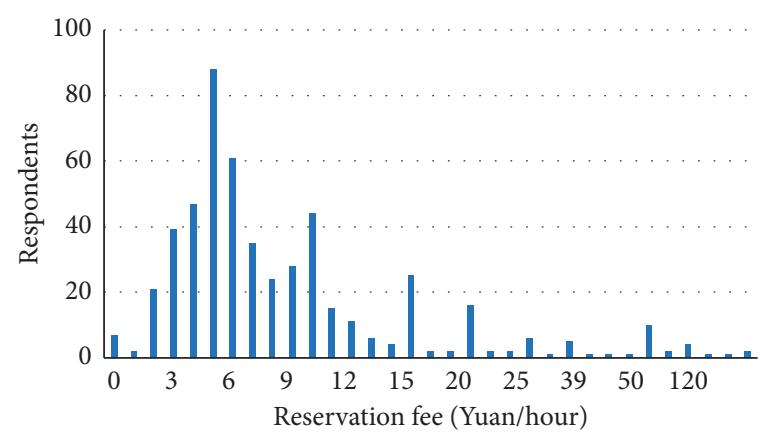

Figure 10: Reservation fee under four scenarios.

\section{Model Calibration and Discussion}

5.1. Value Function Analysis. According to the previous analysis of this survey, we can take several important parameter points as an example for value function analysis: the lowest price reserved is 0 yuan/hour, the ideal price reserved is 5 yuan/hour, and the highest price reserved is 10 yuan/ hour. In Section 5.2, we will analyze the changes in choice behavior and sensitivity to gains or losses when the reference point for the highest price changes. The calibration results of Kahneman and Tversky $\left(\lambda_{i}=0.88\right)[1,28]$ are also adopted in the paper and combined with the established value function model, the following value function graph can be obtained (Figure 11). In order to compare the prospect distribution with Figure 3, we just view partial of Figure 11 like Figure 12.

It can be seen from Figure 12 the area I is "as the reservation price increases, the probability of successful reservation increases", so in this area, as the price increases, the probability of successful reservation increases, travelers will feel the value of their gains increased. When the reserved price is 5 yuan/hour, this point is considered to be the most ideal reserved price. At this time, people feel that they can reserve $100 \%$ of the successful parking spaces with the least amount of money, so they feel that they get the most benefits. Later, in the area II, as the price of reserved parking spaces became higher and higher, people felt that the value of their earnings gradually decreased until the reserved price was 10 yuan/hour, at which time the highest value accepted by the traveler had been reached. In the area III, travelers feel that 


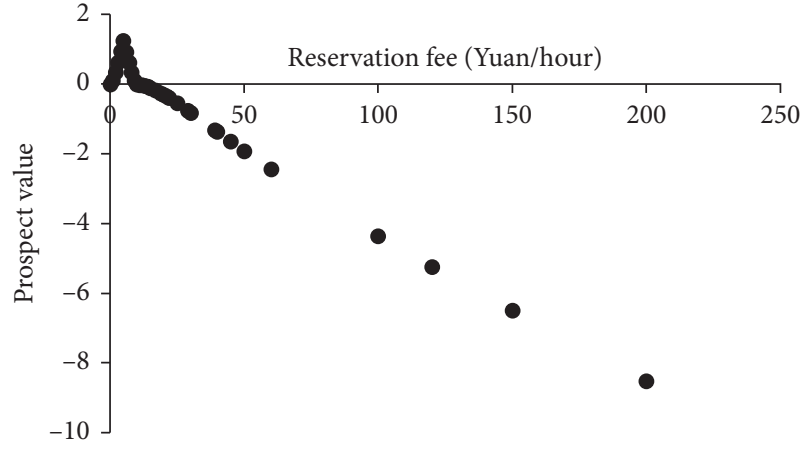

FIGURE 11: The prospect value under different choices of parking reservation fee.

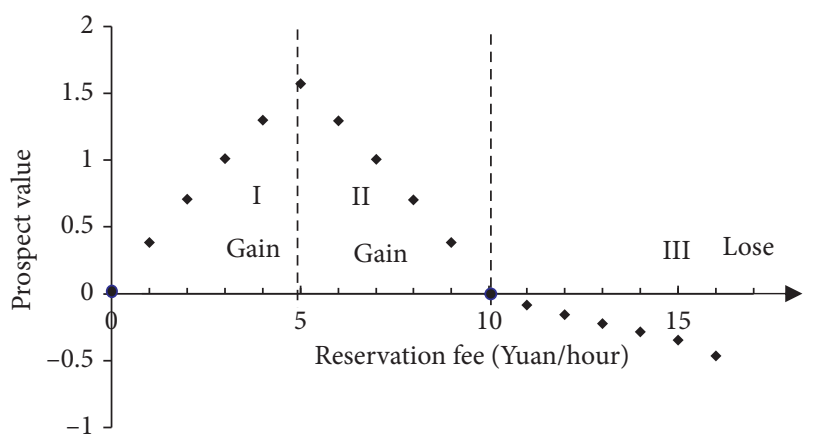

FIgURE 12: The prospect value under different choices of parking reservation fee (partial view).

the price of reserved parking spaces is too high; so as the price increases, the travelers feel more and more loss.

Travelers in area I and area II feel that they are gaining, and in area III, they feel that they are losing, which is consistent with "the value function is the convex function of gain and the concave function of loss" in prospect theory. The established function model is consistent with the trend of the prospect theoretical value function.

5.2. Parameter Calibration of Value Function Model. As can be seen from Table 2, travelers accounted for $76.7 \%$ of the revenue range (area I and area II) and $23.3 \%$ of the loss range (area III). The traveler in the actual survey hopes that the lower the price of reserved parking spaces, the better. In contrast, the parking lot manager hopes that the higher the reserved price, the better.

The maximum likelihood method is used to calibrate the parameters $[1,35]$ when the reference point for the highest price takes 10 yuan, 15 yuan, and 20 yuan, respectively, and the reference point for the lowest reservation price maintains 0 yuan. The calibration results are shown in Table 3 .

$\alpha_{1}, \alpha_{2}>0$ means the travel choice is profitable. $\alpha_{3}<0$ indicates the traveler's choice is lost. The analysis result is consistent with the prospect theory. With the change of the reference point, $\alpha_{1}$ has not changed, indicating that the traveler's sensitivity to the revenue between the minimum reservation fee of 0 yuan and the ideal reservation fee has not changed.
TABLE 2: Travelers' choice distribution of reservation fees.

\begin{tabular}{lcccc}
\hline Reservation fee & Area & Value & Sample size & Percentage (\%) \\
\hline$x_{a}<x_{d}<x_{b}$ & I & Gain & 204 & 39.5 \\
$x_{b}<x_{d}<x_{c}$ & II & Gain & 192 & 37.2 \\
$x_{c}<x_{d}$ & III & Loss & 120 & 23.3 \\
\hline Sum & & & 516 & 100 \\
\hline
\end{tabular}

Sample size includes all the choices for reservation fees under four scenarios (ideal price, highest price, price at $50 \%$ success, and price at $70 \%$ success). Therefore, the total sample size is $129 * 4=516$.

TABLE 3: Calibration results of model parameters.

\begin{tabular}{lccc}
\hline Reference point & $\alpha_{1}$ & $\alpha_{2}$ & $\alpha_{3}$ \\
\hline$(0,10)$ & 0.384 & 0.382 & -0.184 \\
$(0,15)$ & 0.384 & 0.376 & -0.255 \\
$(0,20)$ & 0.384 & 0.258 & -0.398 \\
\hline
\end{tabular}

$T=2.356 \quad \rho^{2}=0.305$

The sample size is 516 , the same as Table 2.

At different reference points, $\alpha_{1}$ is greater than $\alpha_{2}$, indicating that travelers are more inclined to pay less than the ideal price, although there is a risk of unsuccessful reservations. However, an unsuccessful reservation will return the reservation fee, reducing the risk attitude of the traveler. Because the difference of $\alpha_{1}$ and $\alpha_{2}$ is not significant, it means the sensitivities in area I and area II are similar. As the reference point for highest prices becomes larger, $\alpha_{2}$ becomes smaller and smaller, indicating that travelers tend to choose to pay less than the ideal reservation price. The tendency is more obvious. At the same time, the absolute value of $\alpha_{3}$ becomes larger and larger, indicating that travelers are becoming more sensitive to losses if the highest price becomes larger.

\section{Conclusions and Recommendations}

(i) The data processing analysis of the questionnaire survey shows that the traveler's age, gender, monthly income, and other characteristics have a certain impact on the parking reservation choice behavior. Reservation price is the key factor affecting the parking reservation policy. Travelers present different value perceptions of the reserved price of parking spaces, and this process has been verified to be roughly the same as the prospect theoretical model.

(ii) As the reference point for highest prices becomes larger, travelers tend to choose to pay less than the ideal reservation price and become more sensitive to losses.

(iii) The analysis of the traveler's decision on the reserved parking space price shows three different zones. Travelers who choose to reserve prices face risk aversion when faced with gains and risky spirits when faced with losses, which is about the same as the assumptions of prospect theory. It can be found from the model functions and survey data that the 
ideal reserved parking space price in the survey area is 5 yuan per hour, and the ideal reserved parking space in advance is less than 2 hours.

(iv) There are still some limitations and problems that need to be further studied and addressed in the future. The data sample size in this paper is small, and the accuracy of the model based on the survey data needs to be further tested by a larger survey sample. This article focuses on analyzing the impact of the reservation price on the parking reservation policy. Other factors, such as the traveler's perception error of the traveling time from the departure point to the parking lot, have a great influence on the reservation time. In the future, further research can be done in conjunction with the road network traffic conditions.

\section{Data Availability}

The survey data used to support the findings of this study are available from the corresponding author upon request.

\section{Conflicts of Interest}

The authors declare that there are no conflicts of interest regarding the publication of this paper.

\section{Acknowledgments}

This research was sponsored by the National Natural Science Foundation of China (Grant nos. 71961006, 71971005, 51578150, and 51378119), the Social Science Planning Fund of Jiangxi Province, China (Grant no. 18GL37), College Humanities and Social Sciences Fund of Jiangxi Province, China (Grant no. GL18219), the Natural Science Foundation of Beijing, China (Grant no. 8202003), and the Postdoctoral Research Foundation of Southeast University (Grant no. 1121000301).

\section{Supplementary Materials}

The questionnaire of parking reservation, the original survey data, and the data analysis process have been loaded uploaded as supplementary materials. (Supplementary Materials)

\section{References}

[1] Y. Xue, H. Fan, and H. Guan, "Commuter departure time choice considering parking space shortage and commuter's bounded rationality," Journal of Advanced Transportation, vol. 2019, no. 4, pp. 1-7, 2019.

[2] M. Duan, D. Wu, and H. Liu, "Bi-level programming model for resource-shared parking lots allocation," Transportation Letters-The International Journal of Transportation Research, vol. 12, 2020.

[3] Z. Mei, C. Feng, W. Ding, L. Zhang, and D. Wang, "Better lucky than rich? Comparative analysis of parking reservation and parking charge," Transport Policy, vol. 75, pp. 47-56, 2019.

[4] X. Lin and P. Yuan, "A dynamic parking charge optimal control model under perspective of commuters' evolutionary game behavior," Physica A: Statistical Mechanics and Its Applications, vol. 490, no. 490, pp. 1096-1110, 2018.

[5] M. Kaspi, T. Raviv, and M. Tzur, "Parking reservation policies in one-way vehicle sharing systems," Transportation Research Part B: Methodological, vol. 62, pp. 35-50, 2014.

[6] R.-C. Jou, R. Kitamura, M.-C. Weng, and C.-C. Chen, "Dynamic commuter departure time choice under uncertainty," Transportation Research Part A: Policy and Practice, vol. 42, no. 5, pp. 774-783, 2008.

[7] M. Thorhauge, "The role of intention as mediator between latent effects and current behavior:application of a hybrid choice model to study departure time choices," in Proceedings of the Transportation Research Board 95th Annual Meeting, Washington, DC, USA, January 2016.

[8] M. Senbil and R. Kitamura, "Reference points in commuter departure time choice: a prospect theoretic test of alternative decision frames," Journal of Intelligent Transportation Systems, vol. 8, no. 1, pp. 19-31, 2004.

[9] C. Li, Y. Tao, and S. Liu, "A shared parking space optimization model to alleviate China's parking problem considering travelers' tiered credit risk," Transportation Letters, vol. 4, 2019.

[10] C. Shao, H. Yang, Y. Zhang, and J. Ke, "A simple reservation and allocation model of shared parking lots," Transportation Research Part C: Emerging Technologies, vol. 71, pp. 303-312, 2016.

[11] J. Xie, X. Ye, Z. Yang et al., "Impact of risk and benefit on the suppliers' and managers' intention of shared parking in residential areas," Sustainability, vol. 12, pp. 1-17, 2019.

[12] D. C. Shoup, "Cruising for parking," Transport Policy, vol. 13, no. 6, pp. 479-486, 2006.

[13] D. C. E. Ferreira and J. de Abreu E Silva, "Trackling cruising for parking with an online system of curb parking space reservations," Case Studies on Transport Policy, vol. 5, pp. 179-187, 2017.

[14] Q. Tian, L. Yang, C. Wang, and H.-J. Huang, "Dynamic pricing for reservation-based parking system:A revenue management method," Transport Policy, vol. 71, pp. 71-44, 2018.

[15] M.-T. Tsai and C.-P. Chu, "Evaluating parking reservation policy in urban areas: an environmental perspective," Transportation Research Part D: Transport and Environment, vol. 17, no. 2, pp. 145-148, 2012.

[16] D. C. Shoup, "The high cost of free parking," Journal of Planning Education and Research, vol. 17, no. 1, pp. 3-20, 1997.

[17] D. Ayala, "Parking slot assignment games," in Proceedings of the 19th ACM SIGSPATIAL International Conference on Advances in Geographic Information Systems, pp. 299-308, Chicago, IL, USA, November 2011.

[18] M. Kaspi, T. Raviv, M. Tzur, and H. Galili, "Regulating vehicle sharing systems through parking reservation policies: analysis and performance bounds," European Journal of Operational Research, vol. 251, no. 3, pp. 969-987, 2016.

[19] G. Tasseron and K. Martens, "Urban parking space reservation through bottom-up information provision: an agentbased analysis," Computers, Environment and Urban Systems, vol. 64, pp. 30-41, 2017.

[20] H. S. Mahmassani and G.-L. Chang, "On boundedly rational user equilibrium in transportation systems," Transportation Science, vol. 21, no. 2, pp. 89-99, 1987.

[21] T. Li, H. Guan, J. Ma, G. Zhang, and K. Liang, "Modeling travel mode choice behavior with bounded rationality using Markov Logic Networks," Transportation Letters-The International Journal of Transportation Research, vol. 11, no. 2, pp. 1-8, 2019. 
[22] J. J. Soto, L. Márquez, and L. F. Macea, "Accounting for attitudes on parking choice: an integrated choice and latent variable approach," Transportation Research Part A: Policy and Practice, vol. 111, pp. 65-77, 2018.

[23] G. de Moraes Ramos, W. Daamen, and S. Hoogendoorn, "Expected utility theory, prospect theory, and regret theory compared for prediction of route choice behavior," Transportation Research Record, vol. 2011, no. 2230, pp. 19-28, 2011.

[24] W. Liu, H. Yang, and Y. Yin, "Expirable parking reservations for managing morning commute with parking space constraints," Transportation Research Part C: Emerging Technologies, vol. 44, pp. 185-201, 2014.

[25] D. Kahneman and A. Tversky, "Prospect theory: an analysis of decision under risk," Econometrica, vol. 47, no. 2, pp. 263-291, 1979.

[26] A. Tversky and D. Kahneman, "Rational choice and the framing of decisions," The Journal of Business, vol. 59, no. 4, pp. 251-278, 1986.

[27] Z. Li and D. Hensher, "Understanding risky choice behaviour with travel time variability: a review of recent empirical contributions of alternative behavioural theories," Transportation Letters-The International Journal of Transportation Research, vol. 12, no. 3, pp. 1-11, 2020.

[28] W. Song, "Environmentally friendly supplier selection using prospect theory," Sustainability, vol. 9, no. 3, pp. 1-17, 2017.

[29] C. Chorus, "What about behaviour in travel demand modelling? An overview of recent progress," Transportation Letters-The International Journal of Transportation Research, vol. 4, no. 3, 2012.

[30] S. F. A. Batista and L. Leclercq, "The reference point in dynamic Prospect-based User Equilibrium: a simulation study," Transportation Letters-The International Journal of Transportation Research, vol. 12, no. 4, 2020.

[31] J. Zhang, B. Yu, and H. J. P. Timmermans, "Extending relative utility model with multiple reference points to incorporate asymmetric, nonlinear response curvature," in Proceedings of the Transportation Research Board 92nd Annual Meeting, Washington, DC, USA, January 2013.

[32] R. Paleti, P. Vovsha, D. Givon, and Y. Birotker, "Impact of individual daily travel pattern on value of time," Transportation, vol. 42, no. 6, pp. 1003-1017, 2015.

[33] C. Huang, M. Burris, and W. D. Shaw, "Models of transportation choice with risk: an application to managed lanes," Transportation Letters-The International Journal of Transportation Research, vol. 9, no. 2, pp. 1-20, 2016.

[34] A. P. Carrone and J. Rich, "A micro-model of car ownership dynamics: are preferences changing?" Transportation LettersThe International Journal of Transportation Research, vol. 13, no. $1,2020$.

[35] H. Guan, Disaggregate Model-A Tool of Traffic Behavior Analysis, China Communication Press, Beijing, China, 2004. 